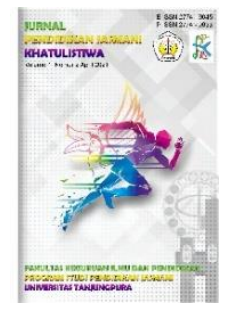

\title{
UPAYA MENINGKATKAN KELINCAHAN MELALUI LATIHAN SHADOW PADA ATLIT PERSATUAN BULUTANGKIS BARENG KARTINI MALANG
}

\section{Efforts To Increase Ability Through Shadow Exercise At The Athletes Of The Badminton Association With Kartini, Malang}

\author{
Ari Gunawan ${ }^{1}$, Elfry ${ }^{2}$ \\ ${ }^{1}$ SD Negeri 11 Alur Bandung, ${ }^{2}$ SMP Negeri 8 Singkawang \\ mgmp.penjaskes2016@gmail.com ${ }^{1}$, elfryapriendy54@guru.smp.belajar.id ${ }^{2}$
}

\begin{tabular}{ll}
\hline Info Artikel & Abstrak \\
\hline \multirow{3}{*}{ Sejarah } & Pada atlet persatuan bulutangkis bareng kartini ditemukan masih kesulitan dalam \\
Artikel: & menghadapi lawan terutama saat atlet mendapatkan bola di depan maupun \\
Diterima & dibelakang masih terlihat kaku, atlet terlihat kesulitan dalam memposisi diri saat \\
(April) (2021) & bola datang di berbagai arah. Hal ini yang disinyalir bahwa atlet tersebut \\
& mengalami kekurangan dalam kelincahan. Untuk mengatasi permasalahan \\
& tersebut diperlukan suatu latihan yaitu latihan shadow. Berdasarkan \\
Disetujui & permasalahan di atas, penelitian ini memiliki tujuan untuk meningkatkan \\
(Mei) (2021) & Kelincahan atlet bulu tangkis Bareng Kartini Malang melalui latihan shadow. \\
& Metode penelitian ini adalah metode Penelitian Tindakan Olahraga (PTO). Hasil \\
Dipublikasikan & Kelincahan atlit persatuan bulutangkis bareng kartini yaitu Untuk kategori sangat \\
(Mei) (2021) & baik sebanyak 20 atlet sebesar 66, 7 \%, untuk kategori Baik sebanyak 7 atlet \\
& sebesar 23,3\%, untuk kategori Sedang sebanyak 1 atlet sebesar 3,3\%, untuk \\
& kategori kurang sebanyak 2 atlet sebesar 26,7\%. Dapat disimpulkan untuk \\
& meningkatkan Kelincahan badminton dapat dilakukan dengan melakukan latihan \\
& shadow. Dalam menerapkan latihan shadow perlu memperhatikan prinsip-prinsip \\
& latihan agar menghindari resiko cedera dan overtraining.
\end{tabular}

Keywords: Increase Agility, Shadow Training, athletes badminton

\section{Abstract}

In badminton union athletes with Kartini, it was found that they still had difficulties in dealing with opponents, especially when the athletes got the ball in front and behind them, they still looked stiff, athletes seemed to have difficulty in positioning themselves when the ball came in various directions. It is alleged that the athlete has a lack of agility. To overcome these problems, an exercise is needed, namely shadow training. Based on the problems above, this study aims to improve the agility of badminton athletes with Kartini Malang through shadow training. The research method is the Sports Action Research (PTO) method. The results of this study indicate that in cycle I and cycle II there was an increase in the agility of athletes in the badminton union with Kartini, namely for the very good category as many as 20 athletes by 66.7\%, for the Good category as many as 7 athletes by 23.3\%, for the Medium category as many as 1 athlete by 3.3\%, for the less category as many as 2 athletes by $26.7 \%$. It can be concluded that improving badminton agility can be done by doing shadow exercises. In applying shadow training, it is necessary to pay attention to the principles of exercise to avoid the risk of injury and overtraining.

(C) 2021 Pendidikan Jasmani, Universitas Tanjungpura

\footnotetext{
Alamat korespondensi

Jl DI. Panjaitan Kpr Taman Sari B.31 Ketapang Kalbar

E-mail

mgmp.penjaskes2016@gmail.com
}

No Handphone 


\section{PENDAHULUAN}

Dunia olahraga semakin tahun semakin menunjukkan eksistensinya di ranah nasional maupun internasional dengan beberapa cabang olahraga yang tidak kita ketahui pernah menduduki gelar juara di kanca internasional (Ashadi, 2014). Dunia olahraga saat ini juga telah bersaing dan tidak mau ketinggalan dalam hal ilmu pengetahuan dan teknologi, yang mana dalam dunia olahraga, senakin tinggi prestasi yang diperoleh, maka pemberian dalam bentuk penghargaan yang di dapatkan pun semakin tinggi. Salah satunya cabang olahraga bulu tangkis yang akan dibahas dalam penelitian ini, semakin terampil dalam memainkan permainan cabang olahraga bulutangkis maka dapat dipastikan penghargaan yang diberikan semakin tinggi (Nugroho, 2019).

Dalam cabang olahraga bulu tangkis memiliki teknik sendiri untuk memainkannya, yang mana bulu tangkis memiliki teknik dasar berupa smash, drive, drop shoot, backhand, forehand, servise dan faktor pendukung seperti Kelincahan badminton yang ditunjang juga disediakan sarana dan prasarana yang memadai (Zulbahri, 2019).

Semakin tahun perkembangan cabang olahraga bulu tangkis di Indonesia semakin populer dan semakin banyak yang menggandrungi dikalangan masyarakat. Sebab, dalam memainkan permainan bulu tangkis ini cukup gampang dimainkan dan mudah dimengerti peraturan yang terdapat dalam permainan bulu tangkis dan untuk sebagian orang yang serius menggeluti cabang olahraga bulu tangkis ini harus memiliki teknik dasar dalam bermain, dalam teknik dasar ini mencakup dengan kelincahan dalam bermain, kecepatan, kondisi fisik yang baik, taktik dalam bermain dan paling penting ialah mental yang sudah terlatih dalam menghadapi pertandingan (Raka, 2015). Yang mana teknik-teknik dasar tersebut adalah faktor yang mempengaruhi seseorang dalam mutu permainan pada saat memainkan permainan bulu tangkis dan teknik dasar tersebut merupakan bagian dari unsur penentu berhasil atau gagal dalam pertandingan yang dilaksanakan.

Pada saat memainkan permainan bulu tangkis, pemain akan berusaha menempatkan shuttlecock ke area lapangan lawan yang kosong agar lawan merasa kesulitan mengembalikan bola, dan pemain dengan begitu akan mendapatkan angka dalam permainan tersebut. Untuk bisa menempatkan shuttlecock, maka diperlukan teknik dasar yang baik. Dalam hal ini, faktor yang mempengaruhi untuk menempatkan shuttlecock yang baik yaitu dengan memiliki keterampilan teknik dasar yang baik, serta kondisi dan karakter fisik yang prima, khususnya pada komponen kelincahan, dayatahan, power, kecepatan dalam bermain bulu tangkis dan memiliki mental yang baik juga. Performa yang baik dengan fisik yang baik dan mental yang sudah siap dalam menghadapi pertandingan (Alif Juanda, 2016).

Dalam bermain bulu tangkis, Kelincahan yang dimaksud dalam permainan bulu tangkis yaitu kemampuan dalam merubah arah dengan tepat dan cepat, menggerakan tubuh dengan cepat dari sisi-ke sisi lainnya. Dengan kata lain unsur kelincahan merupakan salah satu unsur penting dalam bermain bulu tangkis untuk mendapatkan prestasi dalam cabang olahraga tersebut.

Berdasarkan pengamatan peneliti saat atlet sedang melakukan simulasi pertandingan di club Persatuan Bulutangkis Bareng Kartini Malang, penulis menemukan bahwa masih kesulitan dalam menghadapi lawan terutama saat atlet mendapatkan bola di depan maupun dibelakang masih terlihat kaku. Pada bola datang dari lawan, atlet terlihat kesulitan dalam memposisi diri saat bola datang di berbagai arah. Permasalahan ini menjadi masalah utama dalam pertandingan, karena atlet terkesan membuang poin yang disebabkan kesalahan sendiri. Hal ini yang disinyalir bahwa atlet tersebut mengalami kekurangan dalam kelincahan.

Beberapa penjelasan yang sudah dijabarkan di atas bahwa seberapa berpengaruhnya unsur kelincahan dalam bermain bulu tangkis. Peneliti dalam hal ini berasumsi bahwa latihan shadow merupakan keterampilan yang dapat dilatih menjadi lebih baik dalam meningkatkan Kelincahan pada atlet badminton. Oleh karena itu, dalam hasil penelitian yang sejenis, bahwa memberikan sebuah latihan yang mana atlet di arahkan dan Kelincahan badminton guna mengetahui 
seberapa cepat dan lincah yang atlit miliki (Purnama, 2017).

Berdasarkan permasalahan di atas, peneliti mencoba mengatasi permasalahan peningkatan teknik bermain bulu tangkis dengan fokus penelitian "Upaya Meningkatkan Kelincahan Melalui Latihan Shadow Atlit Persatuan Bulutangkis Bareng Kartini Malang.

\section{METODE PENELITIAN}

Dalam penelitian ini, metode yang digunakan yaitu penelitian menggunakan penelitian tindakan olahraga. Penelitian Tindakan Olahraga ini masuk dalam penelitian terapan dan (applied research) yang kemudian menggabungkan antara penelitian, pengetahuan dan tindakan. Action research mempunyai kesamaan dengan penelitian: participatory research, collaborative inquiry, emancipatory research, action learning, dan contextual action research (Mulyatiningsih, 2019). Yang mana dalam Penelitian tindakan Olahraga, peneliti dapat melihat obyek penelitian yaitu atlit melalui pendekatan model latihan yang mana berfungsi untuk meningkatkan Kelincahan bulutangkis dengan latihan shadow. Dalam hal ini tindakan yang sengaja dilakukan melalui latihan shadow, untuk pelaksanaannya para atlet membayangkan suasana pertandingan yang sebenarnya dan pelatih sudah menempatkan shuttlecock sesuai dengan sudah direncanakan. Pengulangan dilakukan sebanyak 8 kali dalam 3 set. Latihan shadow dibantu dengan 3 assisten pelatih agar mengefektifkan waktu dan kesempatan atlet.

\section{HASIL DAN PEMBAHASAN}

Dalam tindakan olahraga ini, penelitian ini berfokus pada atlet Persatuan Bulu Tangkis Bareng Kartini jalan Kelud Gedung Serbaguna Malang, yang memiliki alur sebagai berikut
Perencanaan, dalam perencaaan langkah awal yang dilakukan yaitu penetapan materi yang akan disampaikan guna untuk bahan latihan butu tangkis, kemudian penentuan lokasi latihan juga jadwal pelaksanaan latihan bulu tangkis yang termasuk latihan Kelincahan badminton. Dalam hal ini penelitian dilaksanakan pada bulan Juni - Juli 2018. Tindakan, tindakan disini meliputi seluruh proses kegiatan latihan yang akan dilaksanakan oleh para atlit menggunakan 2 siklus dan sebelum masuk ke dalam siklusI dan siklus II terlebih dahulu di lakukan Pra siklus. Selanjutnya untuk siklus I dilakukan 2 pertemuan, kemudian dilanjutkan ke siklus II yang dilakukan 2 pertemuan. Observasi, observasi dilaksanakan pada proses sedang berlangsungnya latihan. Yang dilaksanakan oleh pelatih maupun dibantu oleh 3 assisten pelatih dan peneliti yang meliputi segala aktifitas atlit, pengembangan dalam memahami materi yang diberikan dan hasil dari latihan yang sudah dilaksanakan. Refleksi, merupakan analisis dari kegiatan yang telah dilaksanakan pada saat refleksi pada siklus I dan akhir siklus II, pelaksanaannya sampai kepada penyusunan rencana perbaikan di siklus latihan berikutnya. Dalam penelitian ini, terdapat kolaborasi yang dilaksanakan oleh pelatih atlit dan peneliti, yang mana pelatih ikut serta dalam membantu step by step dari perencanaan hingga refleksi. Dengan kolaborasi ini, peneliti mendapat hasil yang valid dalam melaksanakan penelitian dan tidak begitu mendapatkan hambatan penelitian yang berarti pada saat pelaksanaannya.

\section{HASIL}

Instrumen tes yang digunakan adalah tes kelincahan dengan lari hilir mudik 4 x 10 meter. Berikut ini adalah tabel nilai tes kecepatan dan kelincahan.

Tabel 1. Profil Hasil Kelincahan pada Pra Siklus

\begin{tabular}{ccc}
\hline Kelincahan & Test 1 & Persen \\
\hline SB & 2 & $7 \%$ \\
\hline B & 7 & $23 \%$ \\
\hline S & 11 & $37 \%$ \\
\hline K & 10 & $33 \%$ \\
\hline
\end{tabular}


Daftar hasil tes kelincahan di atas sebelum diberikan treatment yang mana menyebabkan masih banyak materi yang belum sampai pada target yang diharapkan. Karena hasi penelitian ini dapat dilihat pada tabel 1 bahwa dari 30 peserta diantaranya 10 peserta mendapatkan kategori kurang. Hal ini dapat dinilai bahwa sebelum atlet mendapatkan treatmen, para atlet cenderung pasif.

Tabel 2. Daftar Hasil Tes Kelincahan Badminton Setelah Siklus I

Kategori Jumlah Atlet Persentase

\begin{tabular}{ccc}
\hline $\mathbf{S B}$ & 1 & $3 \%$ \\
\hline $\mathbf{B}$ & 9 & $30 \%$ \\
\hline $\mathbf{S}$ & 15 & $50 \%$ \\
\hline $\mathbf{K}$ & 5 & $17 \%$
\end{tabular}

Dari hasil shadow yang terdapat pada tabel 2 diatas dapat dilihat bahwa setelah di berikan treatmen pada Siklus I, hasil penelitian ini mendapatkan hasil peserta/ atlet yang naik secara signifikan, yang mana dari 10 peserta yang kurang pada pra siklus tabel 1 , pada tahap ini menjadi 5 peserta / atlet yang masuk dalam kategori kurang. Dan yang paling dominan masih dalam kategori sedang sebanyak 15 atlet sebesar 50 persen, artinya perlu penambahan pertemuan atau bisa dikatakan perlu melanjutkan ke siklus II.
Untuk kegiatan di siklus ke II sama dengan siklus I, akan tetapi yang menjadi pembedanya adalah saat sebelum melaksanakan kegiatan tersebut pelatih bersama peneliti memberikan motivasi dan koreksi gerakan atlet dalam melakukan latihan shadow, menenangkan siswa yang masih grogi karena diawasi oleh pihal luar. Sampai dengan refleksi pada siklus II, tampak sekali terjadinya perubahan dalam penampilan tiap-tiap atlet. Hal ini dapat dilihat pada tabel 3 di bawah ini.

Tabel 3. Daftar Hasil Tes Kelincahan Badminton Setelah Siklus II

\begin{tabular}{ccc}
\hline Kategori & Jumlah Atlet & Persentase \\
\hline SB & 20 & $66,7 \%$ \\
\hline B & 7 & $23,3 \%$ \\
\hline S & 1 & $3,3 \%$ \\
\hline K & 2 & $6,7 \%$ \\
\hline
\end{tabular}

Pada test setelah siklus 1 dan 2 hasil sudah memenuhi harapan, yakni adanya peningkatan Kelincahan atlit persatuan bulutangkis bareng kartini jadi tidak perlu di lanjutkan dengan siklus ke 3 karena sudah ada peningkatan pada siklus 1 dan siklus 2 dan penelitian ini dapat di anggap berhasil untuk latihan menggunakan unsur latihan shadow. Hasil ini dapat terlihat pada tabel 3 di atas. Untuk kategori sangat baik sebanyak 20 atlet sebesar 66, $7 \%$, untuk kategori Baik sebanyak 7 atlet sebesar 23,3\%, untuk kategori Sedang sebanyak 1 atlet sebesar $3,3 \%$, untuk kategori kurang sebanyak 2 atlet sebesar 26,7\%, yang artinya terjadi peningkatan jumlah atlet yang merasakan dampak latihan shadow yang diterapkan oleh peneliti.

\section{PEMBAHASAN}

Hasil penelitian menunjukkan bahwa pada latihan shadow dapat meningkatkan Kelincahan badminton. Terdapat pada tabel diatas bahwa hasil penelitian ini memiliki peningkatan dari siklus I ke siklus ke II yang masing-masing siklus melaksanakan 2 kali pertemuan.

Dari tabel di atas nampak sekali adanya peningkatan Kelincahan atlit, ini dilihat dari perbedaan kelincahan atlit dan peningkatan pada saat Diberi tindakan latihan shadow, dari hasil penelitian (Saputra \& Sepdanius, 2019) yang serupa bahwa membuktikan bahwa terdapat pengaruh yang signifikan (meningkat) dari pemberian latihan Shadow terhadap Peningkatan 
Kelincahan Atlet Bulutangkis PB. Lima Puluh Kota. Dan lebih spesifik lagi menurut (Rahman \& Warni, 2017) bahwa untuk meningkatkan kelincahan dalam berrmain bulutangkis diperlukan latihan menggunakan shadow 8 pada usia antara 12-15 tahun. Dan penggunaan latihan shadow 8 harus juga memperhatikan prinsip-prinsip dalam latihan agar menghindari overtraining, cedera di usia muda dan meningkat kecepatan dan kelincahan atlet bulutangkis dalam bermain. Selain latihan shadow dapat meningkatkan kelincahan, latihan shadow juga dapat meningkatkan keseimbangan dalam bermain bulutangkis. Hasil penelitian (Marpaung \& Manihuruk, 2021) memaparkan bahwa terdapat pengaruh latihan shadow terhadap peningkatan kelincahan dan keseimbangan bermain bulutangkis pada Mahasiswa Fakultas Ilmu Keolahragaan Universitas Negeri Medan. Oleh sebab itu, latihan shadow memiliki dampak yang luar biasa terhadap kelincahan, kecepatan maupun keseimbangan dalam bermain bulutangkis yang memerlukan ketiga komponen tersebut. Walaupun masih perlu komponen latihan lain perlu ditingkat juga, dan tidak boleh dilupakan, latihan shadow juga harus memperhatikan prinsip-prinsip latihan agar menghindari resiko cedera dan overtraining.

\section{SIMPULAN}

Hasil penelitian di atas menunjukkan bahwa untuk meningkatkan Kelincahan badminton dapat dilakukan dengan melakukan latihan shadow. Selain meningkatkan kelincahan, latihan shadow dapat meningkatkan kecepatan dan keseimbangan dalam bermain bulutangkis, selain itu menerapkan latihan shadow perlu memperhatikan prinsip-prinsip latihan agar menghindari resiko cedera dan overtraining.

\section{DAFTAR PUSTAKA}

Alif Juanda, H. (2016). Kecepatan dan Akurasi Shuttlecock Pada Jump Smash Dengan Loncatan Vertikal dan Parabol Depan Dalam Bulutangkis. Jurnal Terapan Ilmu Keolahragaan, Vol. 1.

Ashadi, K. (2014). Implementasi Fisiologi Olahraga Pada Olahraga Prestasi. Ilmu
Keolahragaan Nasional.

Marpaung, D. R., \& Manihuruk, F. (2021). Sains Olahraga: Jurnal Ilmiah Ilmu Keolahragaan. Sains Olahraga: Jurnal Ilmiah Ilmu Keolahragaan, 5(1), 40-50. http://jurnal.unimed.ac.id/2012/index.ph $\mathrm{p} / \mathrm{so}$

Mulyatiningsih, E. (2019). Metode Penelitian Tindakan Kelas. Ilmu Keolahragaan Nasional, Vol. 8.

Nugroho, A. (2019). Pengaruh Metode Latihan dan Kelincahan Terhadap Kecepatan Reaksi Atlet Bola Voli Remaja.

Purnama, H. (2017). Evaluasi Program Pembinaan Atlet Pekan Olahraga Nasional abang Olahraga Bulutangkis Provinsi Sumatera Selatan. Journal of Physical Education and Sports, Vol. 3.

Rahman, T., \& Warni, H. (2017). Pengaruh latihan shadow 8 terhadap agility pada pemain bulutangkis pb. Mustika banjarbaru usia 12 - 15 tahun. Multilateral Jurnal Pendidikan Jasmani Dan Olahraga, 16(1). https://doi.org/10.20527/multilateral.v1 $6 i 1.3660$

Raka, B. (2015). Analisis Kelebihan dan Kekurangan Keterampilan Teknik Bermain Bulutangkis Pada Pemain Tunggal Putra Terbaik Indonesia Tahun 2014. Jurnal Kesehatan Olahraga, Vol. 3.

Saputra, T. W., \& Sepdanius, E. (2019). Pengaruh Latihan Shadow Terhadap Peningkatan Kelincahan Atlet Bulutangkis PB. Lima Puluh Kota. JURNAL STAMINA, 2(9), 171-177. https://doi.org/10.24036/JST.V2I5.364 
Zulbahri. (2019). Metode Practice Style dan Guided Discovery Style Serta Keterampilan Teknik Dasar Atlet
Bulutangkis. Ilmu Kesehatan Dan Sains, Vol. 1. 